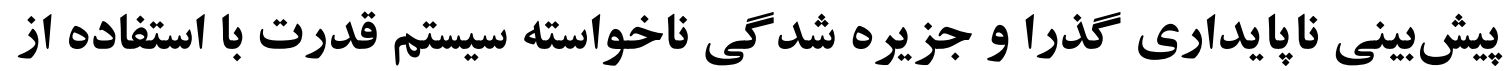 PMU اطلاعات
}

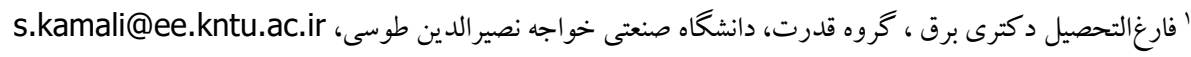

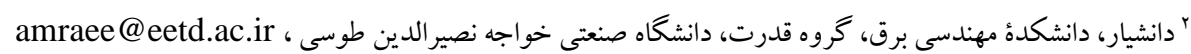

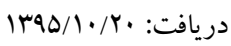

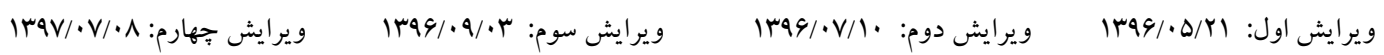
يذيرش:

$$
\begin{aligned}
& \text { جكيده: در اين مقاله يك الكوريتم براى بيشبينى جزيره شدگى ناخواسته ارائشده است. در اين الكوريتم براى بيشبينى جزيره }
\end{aligned}
$$

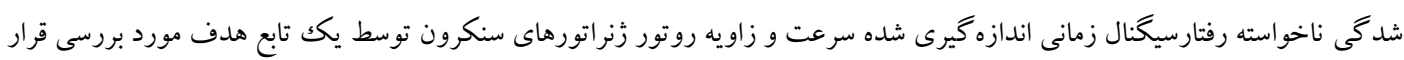

$$
\begin{aligned}
& \text { كرفته است. ساختار اين تابع هدف به نحوى تعيين شده است درلحظه تغييرات تويولوزى شبكه داراى تغييرات زانويى مىباشد. در راستاى }
\end{aligned}
$$

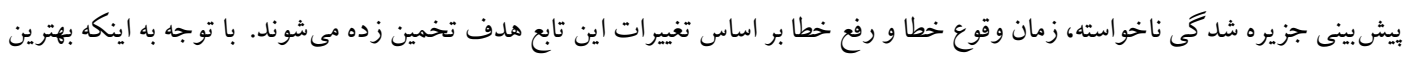

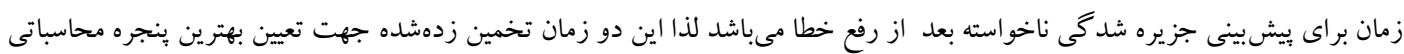

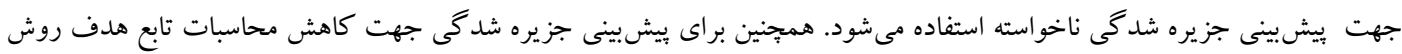

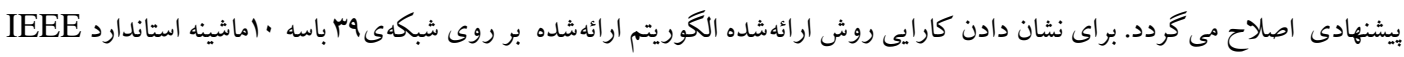

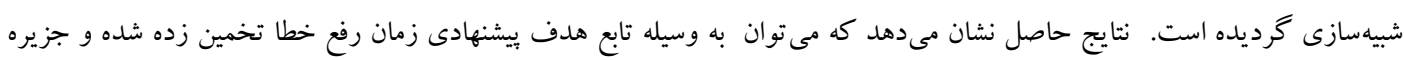

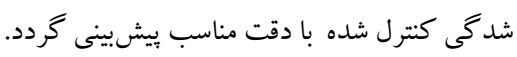

$$
\begin{aligned}
& \text { كلمات كليدى: جزيره شدىى،يشيشي،نإيايدارى كذرا، بهينهسازى }
\end{aligned}
$$

\section{Prediction of transient instability and unplanned islanding using phasor measurements data}

\section{Sadegh Kamali, Turaj Amraee}

\begin{abstract}
To predict unplanned islanding, rotor angle and speed time series have been used. Times of fault occurrence and clearance are estimated using monitoring system response based on the variation of phasor measure data. The estimated times of fault occurrence and clearance are used to determine suitable calculation window for uncontrolled islanding prediction. The proposed algorithm is applied to IEEE 39 bus test system. The result shows that the objective function can be used to estimate fault occurring and clearance time to predict unplanned islanding.
\end{abstract}

Keywords: Islanding, Prediction, Transient instability, Optimization. 
با توجه به اتفاقاتى كه ذكر شد، تشخيص و يِيشبينى جزيره شدكى

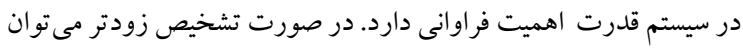

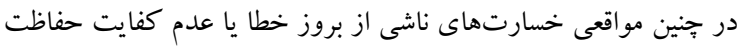

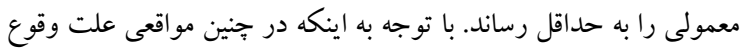

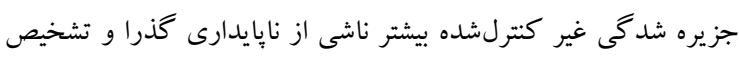

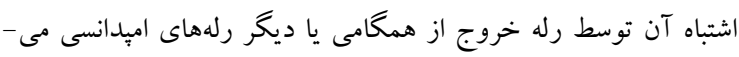

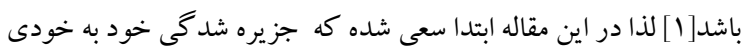

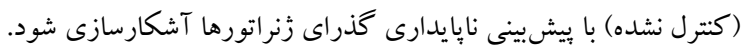

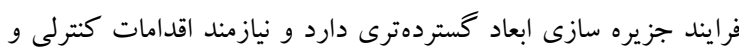

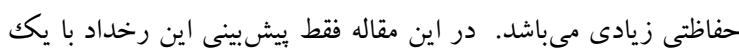
مدل بهينه مدنظر مىباشد جزئيات كنترل جزيره سازى و ابعاد آن مورد بحث قرار نمى گيرد. هر طرح كنترل جزيره سازى داراى دو بخش يخ "تعيين

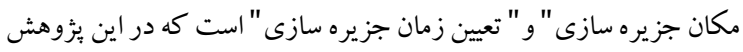

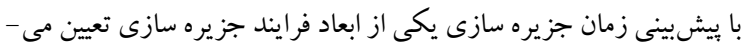

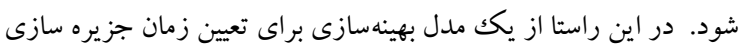
استفادهده است.

جزيره ســازى كنترلشـــده آخرين ابزار كنترلى براى كنترل جزيره

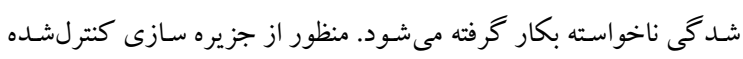

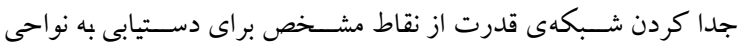

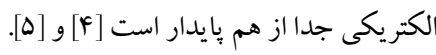

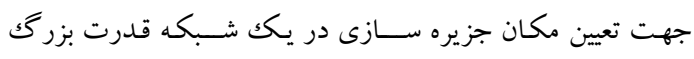

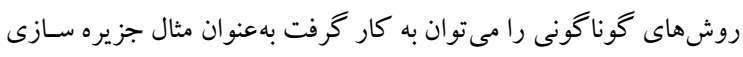

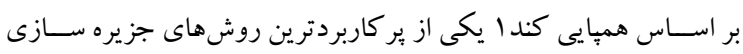

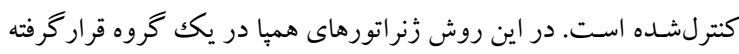

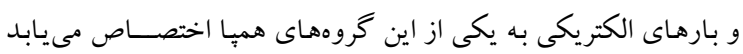

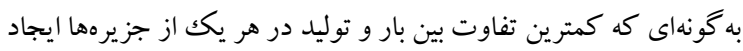

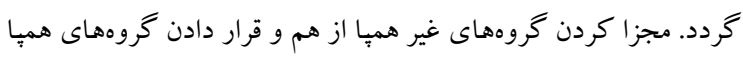

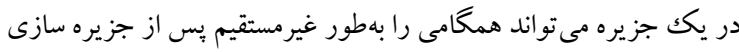

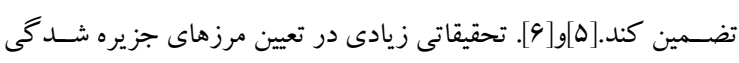

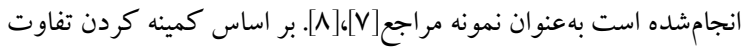

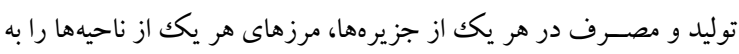

دست آورددهاند.

باوجود اينكه مطالعات كمى براى تشخص زمان جزيره سازى انجام

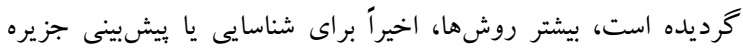

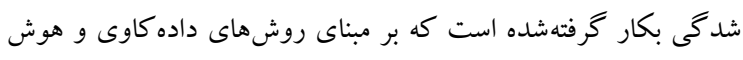
مصنوعى به كمكك اطلاعات غير برخط استوار بوده است [F]. بهعنوان مثال

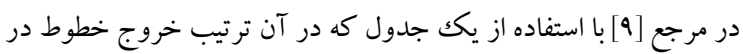

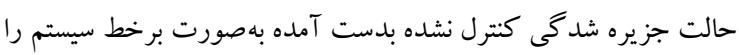

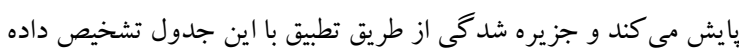

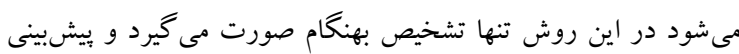

- 1 - (1قدمه

سيستمهاى قدرت در برخى نقاط جهان در خند دهه اخير خاموشىهاى

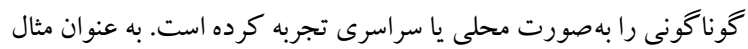

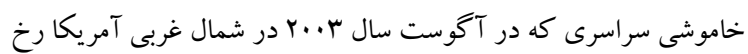

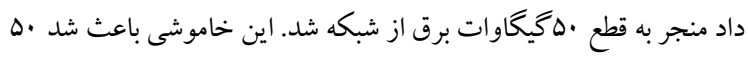

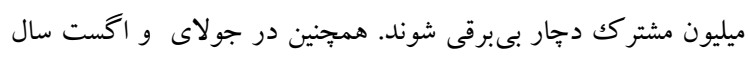

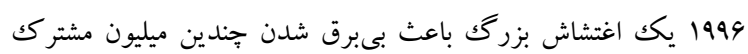

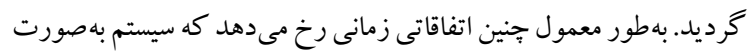

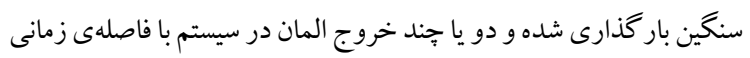

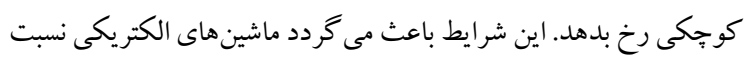

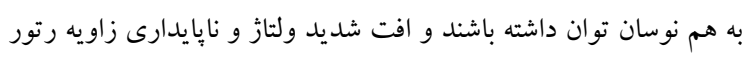

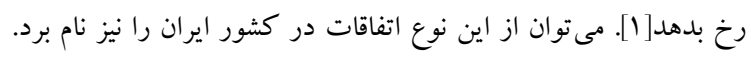

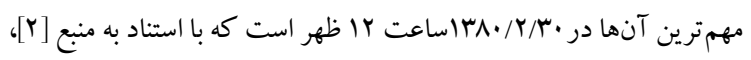

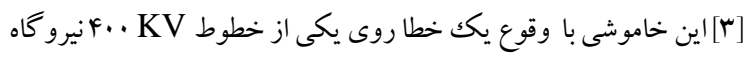

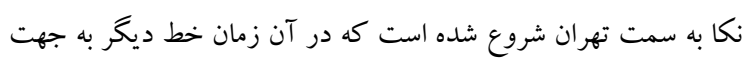

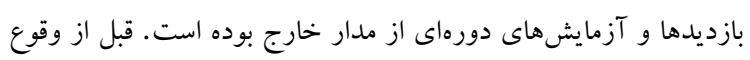

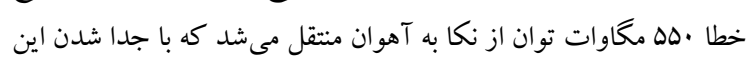

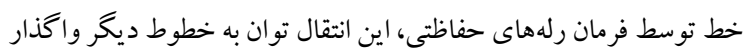

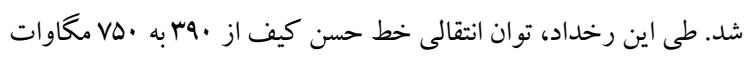

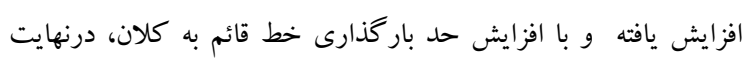

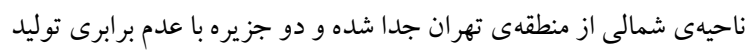

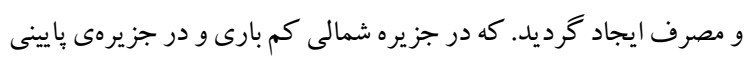

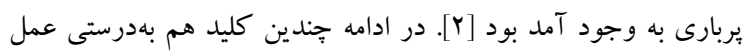

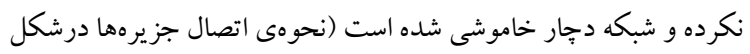

ا نشان دادهشده است) [ب].

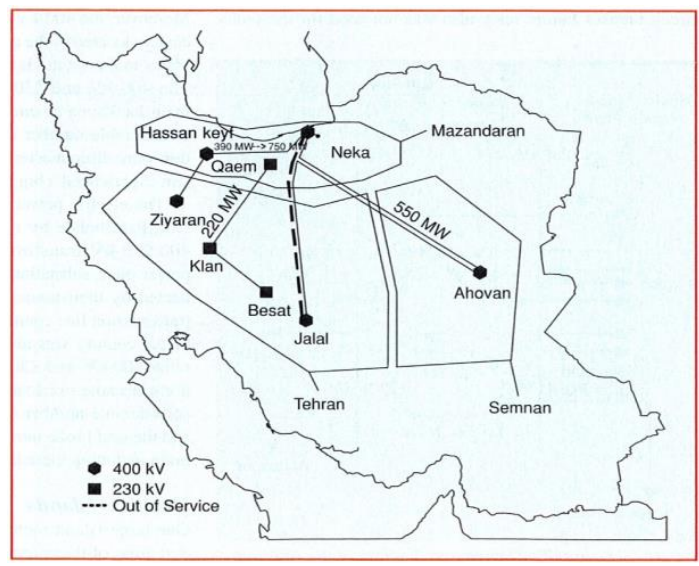

شكل ا: مرز بين جزيرههاى غير كنترلشده در سيستم قدرت كشور

ايران [r]

${ }^{1}$ Slow Coherency 
شود و در مرحلهى دوم با استفاده از تشخيص رفع خطا از تغييرات تابع

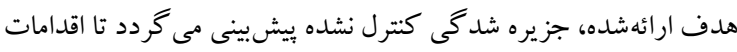
تكميلى جهت كنترل اين رخداد صورت كيردا

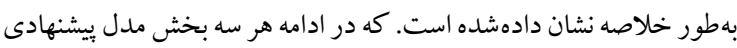
تشريح مى گردد.

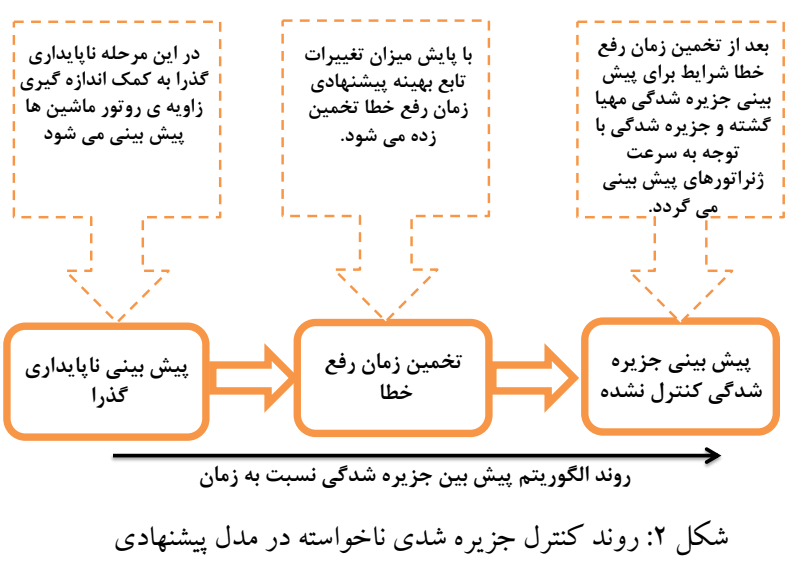

\section{ץ- بيش بينى نإِايدارى كذرا}

با توجه به اينكه در هر سيستم قدرت تحت اغتشاش تغييرات زاويهى روتور

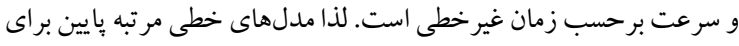

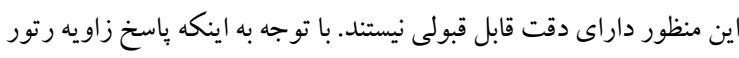

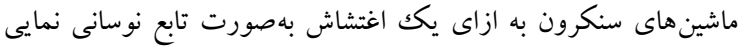

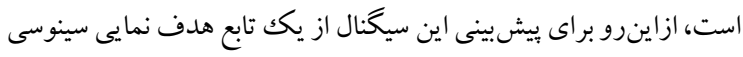

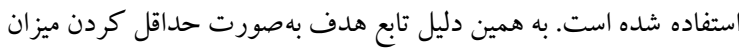

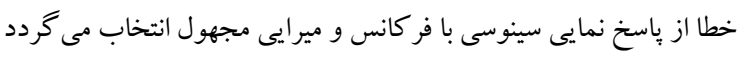

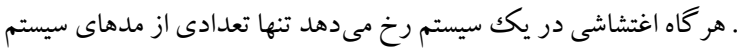

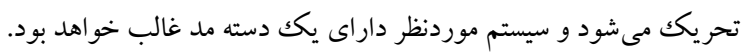

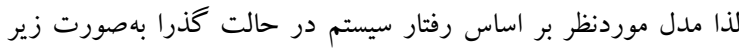
ييشنهاد داده مى شود:

$$
O_{-} F=\sum_{N=1}^{N_{t}}\left|\left[A+\sum_{n=1}^{k} B_{n} e^{\alpha_{n} t} \times \sin \left(\omega_{n} t+\varphi_{n}\right)\right]-\mathrm{y}_{N}\right|
$$

كه در معادلهى بالال[مال

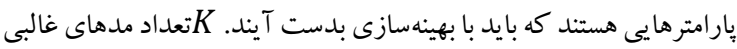
است كه در پِاسخ موردنظر تحريك شدهاند. محاسباتى است و از رابطهى زير بدست مى آيد.

$$
N_{t}=C W_{t} / \Delta t
$$
كه در اين رابطه CW طول هر بنجرهى محاسباتى است و $\Delta t$ تفاوت زمانى
صورت نمى گيرد. مقالات كنفر انسى متعددى در اين زمينه موجود است

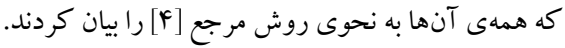

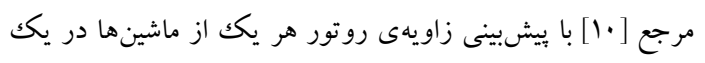
محدودهى مشخص زمان جزيره سازى را يِيشبينى مى كند. در اين مقاله

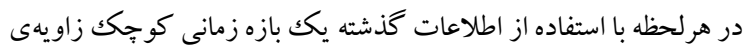

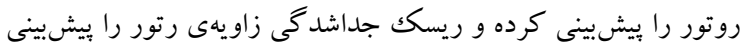
مى كند. در [11] به بيشبينى جزيره شدگى بر اساس زاويه روتور ماشينها برداخته

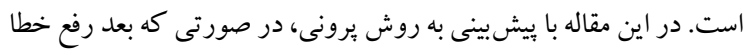

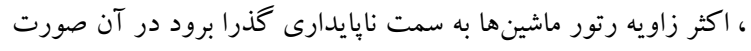

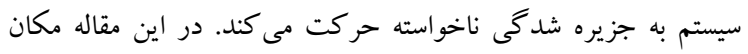
جزيره شدكى هم به روش هم يايى تشخيص داده مىشود.

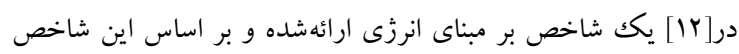

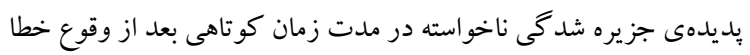
ييشبينى مى شود. به علت اينكه اين شاخص از جنس انرزى است روش روش

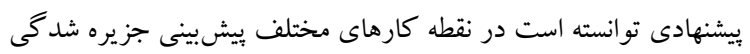

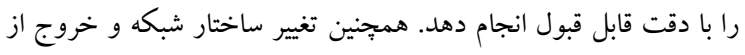

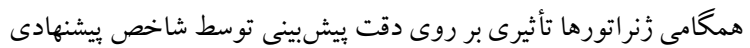
نداشته است. در [rا] با توجه به اطلاعات غير برخطى كه بر اساس شبيهسازى در

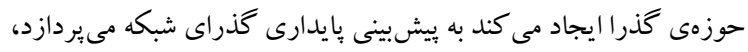

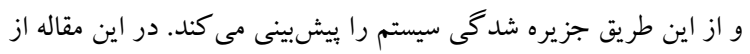
روش ANFIS جهت ويشبينى يايدارى شبكه استفاده كرده است.

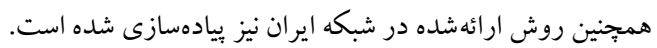

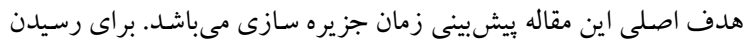

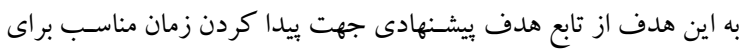
ييشبينى زمان جزيره شدگى استفادهشده است. بهينه سازى هاى انجامشده

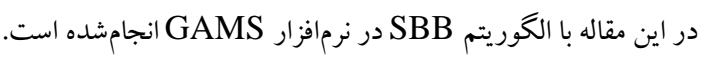

\section{r- التوريتم ارائهده براى بيشبينى جزيره شدكى ناخواسته}

در سيستم قدرت نايايدارى گذرا و خروج از هم گامى زنراتورها مى تواند باعث وقوع رخدادهاى بزر گترى همجون خاموشى سراسرى يا جزيره

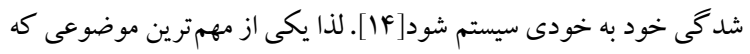

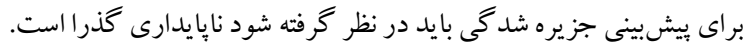

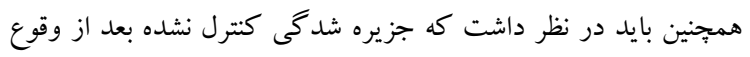
جندين نايايدارى گذرا در سيستم خود را نشان مى دهد. كه خسارات زيادى

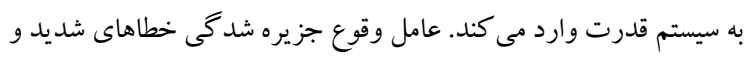
در يى آن عملكرد اشتباه رله هاى حفاظتى مى باشد [1ه]. در مدل ارائهشده

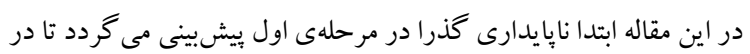

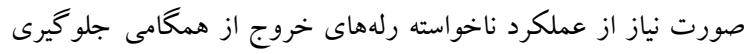


زاويهى روتور را مىتوان براى زمانهاى بعدى بيشبينى كرد بيشبينى

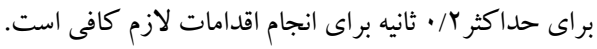

\section{ع-شناسايى وقوع خطا، رفع خطا}

با توجه به مدل ارائه شده در بخش ץ مىتوان زمان وقوع خطا و رفع خطا را

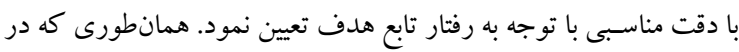

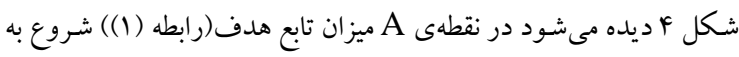

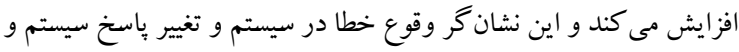

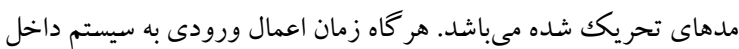

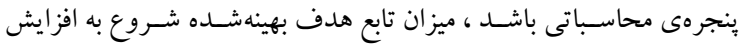

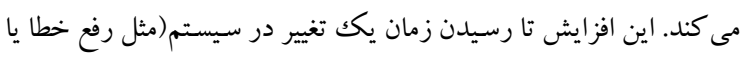

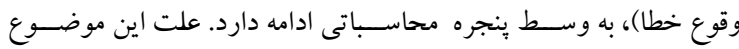

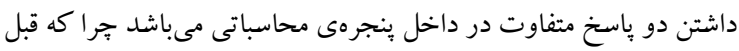

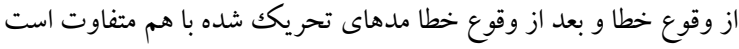

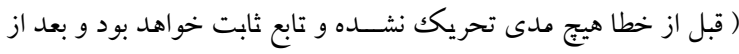

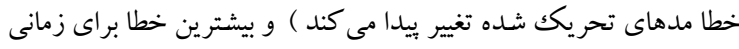

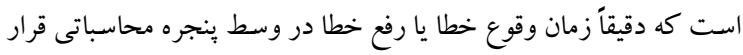

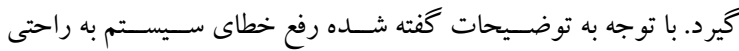

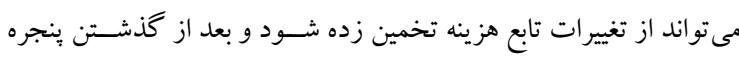

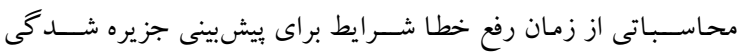

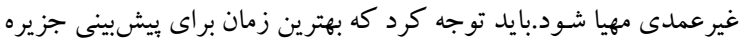

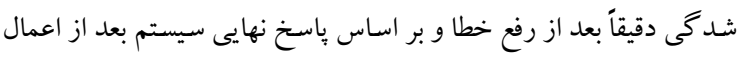

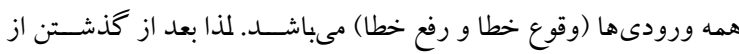

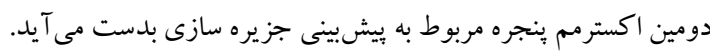

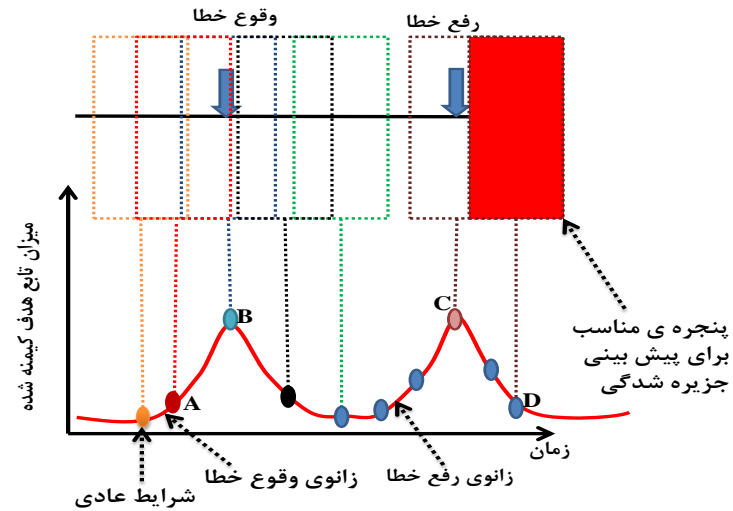

شكل \&:نحوهى تغيير تابع هدف در روند بِيشبينى

0- بروســى كارايى مدل بهينه ارلئهـــه و نتايج شبيهسازى
بين دو اندازهيرى متوالى مىباشد كه با توجه به اطلاعات 1 بMU, و و

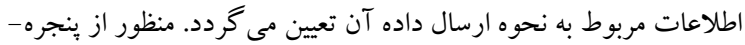

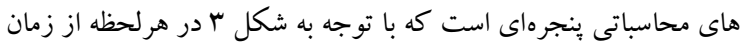

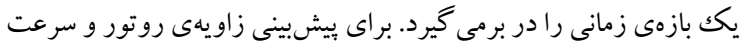

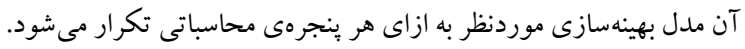

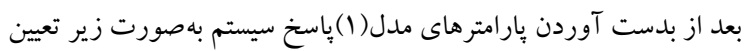
مى گردد.

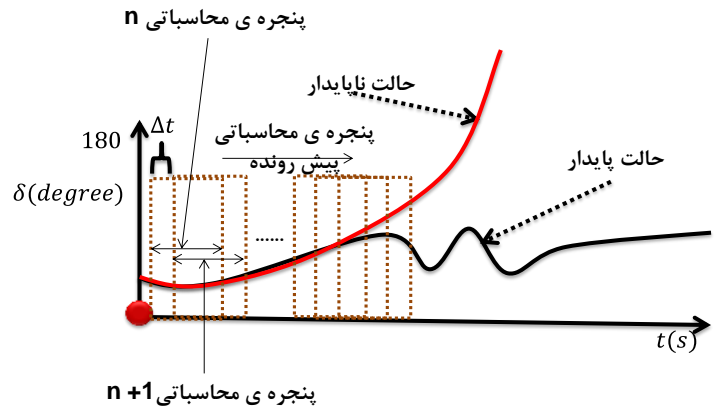

شكل r: نحوهى حر كت كردن بنجرهى محاسباتى براى بيشبينى نمودار

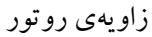

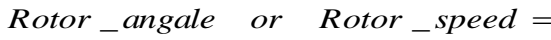
$\left.A+\sum_{n=1}^{k} B_{n} e^{\alpha_{n} t} \times \sin \left(\omega_{n} t+\varphi_{n}\right)\right]$

بايد توجه داشت كه انتخاب مقادير بزرك براى بنجرهى محاسباتى باعث : بـ

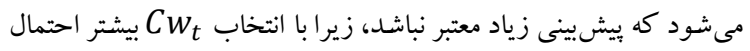

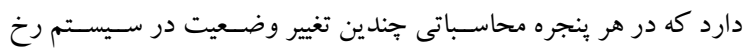

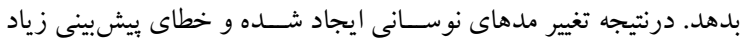

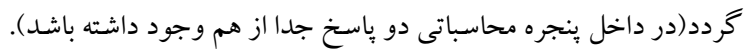

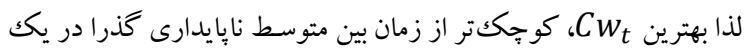

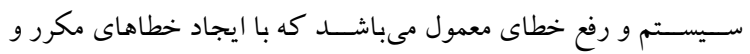

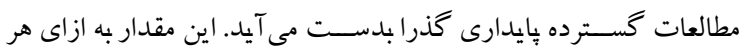

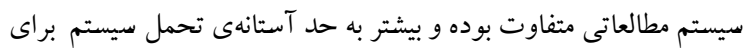

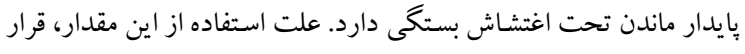

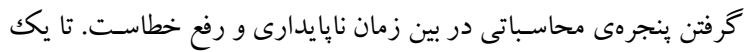

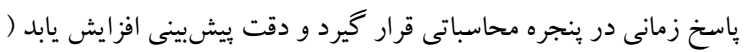

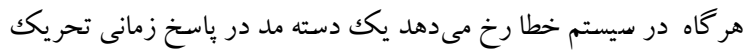

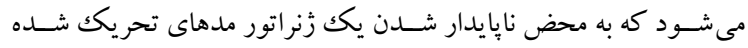

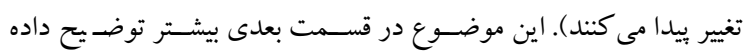

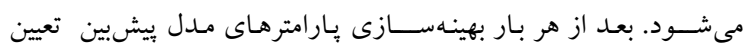

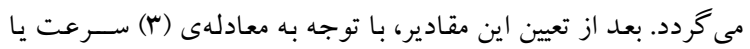

${ }^{1}$ Phasor Measurement Unit 
شـكل 9: نحوهى تغييرات زاويه روتور ماشــين ا در اثر خطاى سـه فاز متقارن اعمالشده به باس 19 با رفع خطاى •هاميلىثانيه با خروج خط

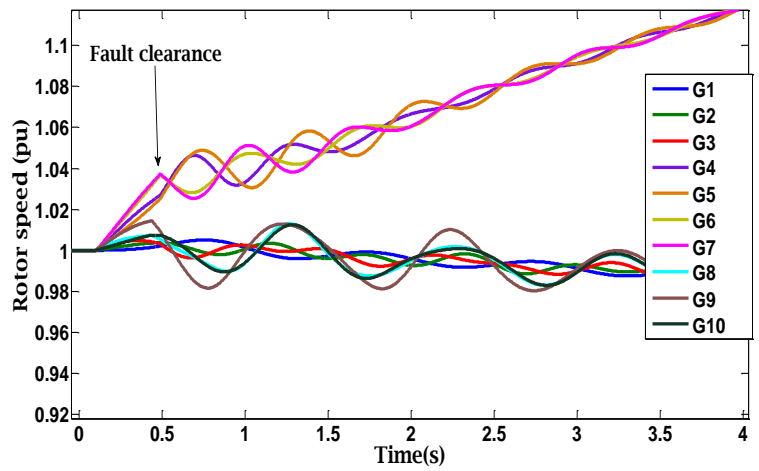

شـكل V: نمودار سـرعت زنراتورهاى شبكه هץ باسـه بعد از اعمال خطاى

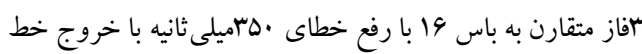

جدول ا: مدهاى تحريكك شــده در هر يكك از ياســخها، به ازاى خطاى

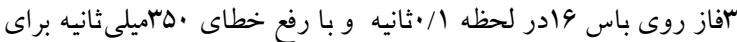
بيشبينى زاويه روتور

\begin{tabular}{|c|c|c|c|}
\hline مت متير هاى حالت & ماشين & متثير هاى حالت & ماشين \\
\hline $\begin{aligned} O_{-} F & =0.234 \\
A & =46.441 \\
k & =3 \\
B & =\left[\begin{array}{lll}8.5360 & 8.5470 & 8.5740\end{array}\right] \\
\alpha & =\left[\begin{array}{lll}3.0030 & 3.0620 & 3.2450\end{array}\right] \\
\omega & =\left[\begin{array}{lll}4.1450 & 4.1870 & 5.2030\end{array}\right] \\
\varphi & =\left[\begin{array}{lll}-1.0710 & -1.0520 & -1.4850\end{array}\right]\end{aligned}$ & 4 & $\otimes$ & 1 \\
\hline 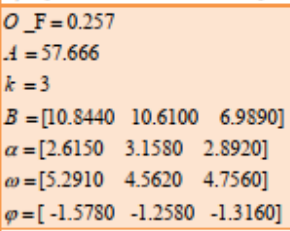 & $v$ & $\begin{array}{l}O_{-} \mathrm{F}=1.0025 \\
A=17.315 \\
k=1 \\
B=[7.454] \\
\alpha=[-0.123] \\
\omega=[6.420] \\
\varphi=[-2.220]\end{array}$ & $r$ \\
\hline $\begin{array}{l}O_{-} \mathrm{F}=0.110 \\
A=37.38 \\
k=3 \\
B=\left[\begin{array}{lll}5.4200 & 5.2740 & 4.4760\end{array}\right] \\
\alpha=\left[\begin{array}{lll}0.5380 & 0.7510 & 0.1840\end{array}\right] \\
\omega=\left[\begin{array}{lll}6.0000 & 6.0000 & 5.52600\end{array}\right] \\
\varphi=\left[\begin{array}{lll}-1.921 .9210 & -2.0810\end{array}\right]\end{array}$ & $\wedge$ & $\begin{array}{l}O_{\_} F=1.008 \\
A=29.571 \\
k=1 \\
B=[9.206] \\
\alpha=[0.324] \\
\omega=[6.850] \\
\varphi=[-2.240]\end{array}$ & $r$ \\
\hline $\begin{array}{l}O_{-} F=0.102 \\
A=45.2280 \\
k=3 \\
B=\left[\begin{array}{lll}6.9610 & 6.9610 & 6.9190\end{array}\right] \\
\alpha=\left[\begin{array}{lll}1.5750 & 1.5750 & 1.4610\end{array}\right] \\
\omega=\left[\begin{array}{lll}6.0000 & 6.0000 & 5.0520\end{array}\right] \\
\varphi=\left[\begin{array}{lll}-1.1 .8890 & -1.8890 & -1.64400\end{array}\right]\end{array}$ & 9 & $\begin{array}{l}O_{-} \mathrm{F}=0.234 \\
A=52.1014 \\
k=3 \\
B=\left[\begin{array}{lll}0.2920 & 9.2460 & 9.2920]\end{array}\right] \\
\alpha=\left[\begin{array}{lll}2.3600 & 2.1790 & 2.3600\end{array}\right] \\
\Theta=\left[\begin{array}{lll}5.0240 & 4.4410 & 5.0260\end{array}\right] \\
Q=\left[\begin{array}{lll}-1.5710 & -1.4390 & -1.5000\end{array}\right]\end{array}$ & ${ }^{f}$ \\
\hline $\begin{array}{l}O_{-} \mathrm{F}=0.060 \\
A=20.6850 \\
k=3 \\
B=\left[\begin{array}{lll}-5.3540 & -4.4950 & -3.5300\end{array}\right] \\
\alpha=\left[\begin{array}{lll}2.6350 & -3.9140 & 1.2600\end{array}\right] \\
\omega=\left[\begin{array}{lll}6.2350 & 5.1790 & 7.8730\end{array}\right] \\
\varphi=\left[\begin{array}{lll}0.5478 & 1.4348 & 1.5758\end{array}\right]\end{array}$ & 1. & $\begin{array}{l}O_{-} F=0.234 \\
A=46.441 \\
k=3 \\
B=\left[\begin{array}{lll}8.5360 & 8.5470 & 8.5740]\end{array}\right] \\
\alpha=\left[\begin{array}{lll}3.0030 & 3.0620 & 3.2450\end{array}\right] \\
\Theta=\left[\begin{array}{lll}4.1450 & 4.1870 & 5.2030\end{array}\right] \\
\phi=\left[\begin{array}{lll}-1.0710 & -1.0520 & -1.4850\end{array}\right]\end{array}$ & $\Delta$ \\
\hline
\end{tabular}

در اين قسـمت براى نشـان دادن كارايى روش ييشـنهادى اين روش را با

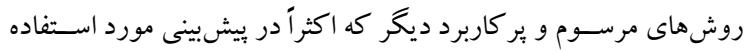

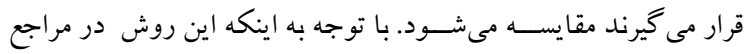

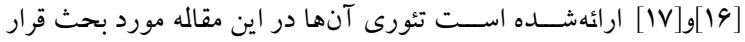

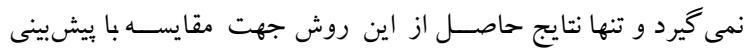

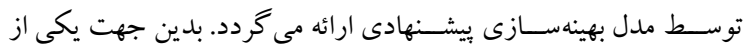

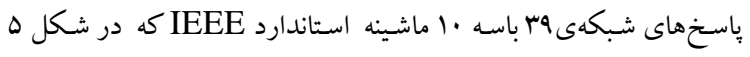

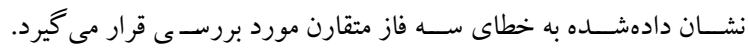

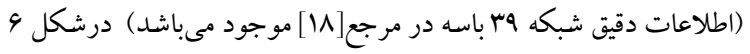
نحوهى تغييرات زاويهى روتور سيستم بعد از اعمال خطاى سه فاز متقارن

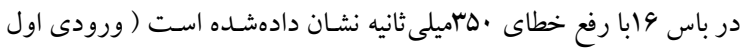

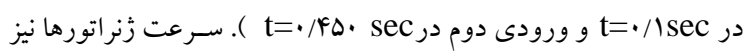

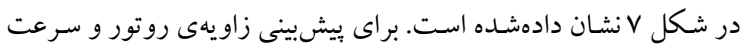

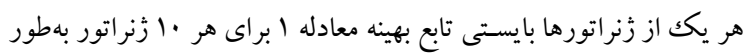

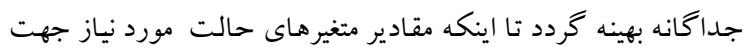

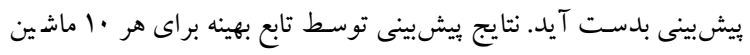
قبل از رفع خطا در جدول آمده اسـت. همانطورى كه در جدول بـ اديده

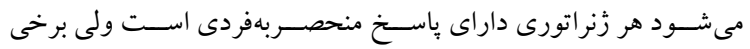

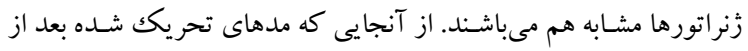

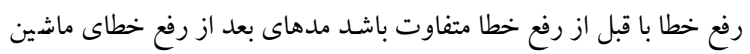
ا تا • انيز در جدول ب آمده است.

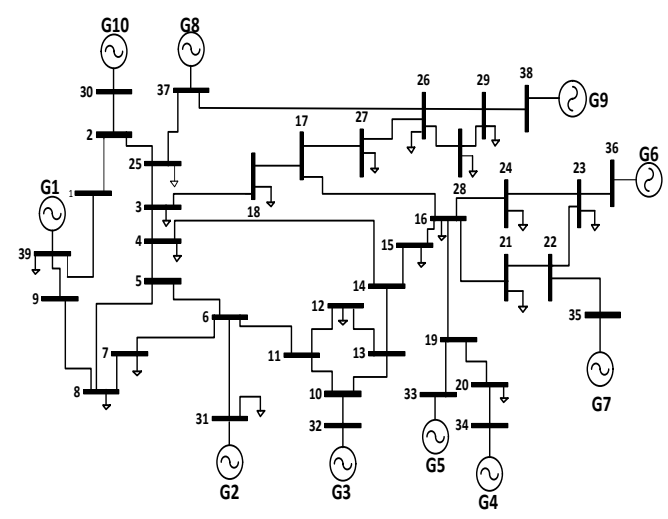

شكل ه:شبكه هץ باسه • أماشينه استانداردIEEE

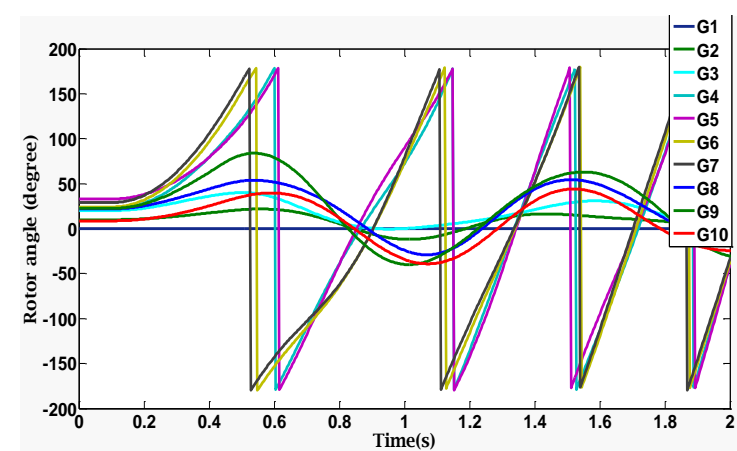


براى همه زنراتورها تابع هدف كفته شده در معادله ا را بهينه نموده و زاويه

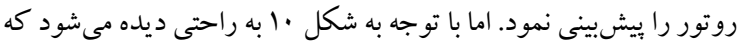

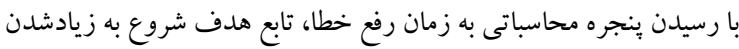

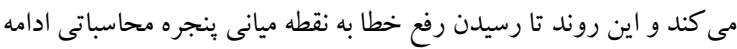

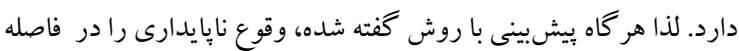

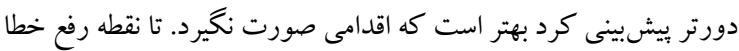
از داخل بنجره محاسباتى خارج شود، خرا كه ممكن است رفتار ياسخ

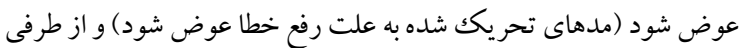

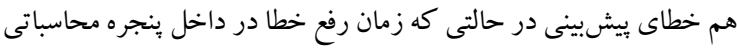

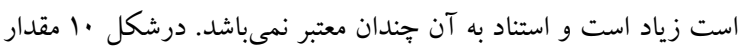
ماكزيمم مربوط به زمانى است كه رفع خطا دقيقاً در وسط بنجره محاسباتى

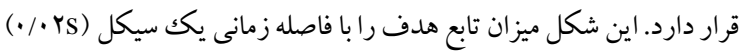

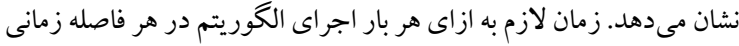

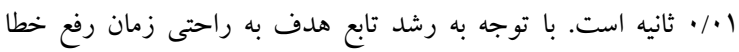

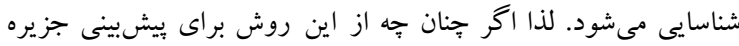

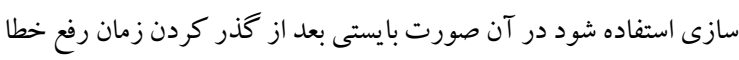

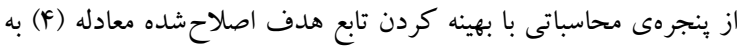
ييشبينى جزيره شدكى يرداخت.

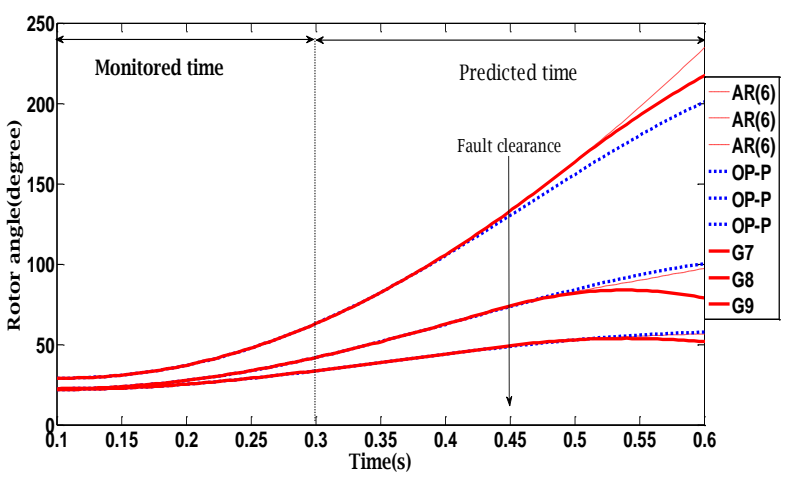

شكل م: ييش بينى زاويهى روتور زنراتورهاى V، م و 9 با مدل بهينه

رائهده و AR درجهى 4

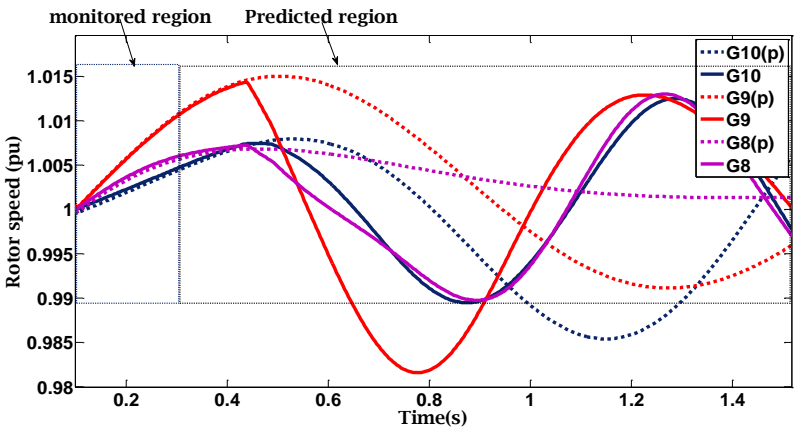

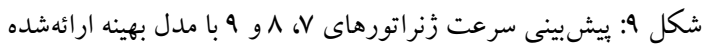

9 AR a
جدول r: مدهاى تحريك شده بعد از رفع خطا در لحظه •

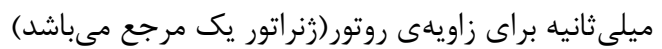

\begin{tabular}{|c|c|c|c|}
\hline متغير هاى حالت & شماره & متغير هاى حالت & شماره \\
\hline $\begin{array}{l}O_{-} \mathrm{F}=0.187 \\
A=6.713 \\
k=1 \\
B=[2.805] \\
\alpha=[0.712] \\
\omega=[3.750] \\
\varphi=[1.0178]\end{array}$ & 9 & $\otimes$ & 1 \\
\hline $\begin{array}{l}O_{-} \mathrm{F}=0.226 \\
A=5.384 \\
k=1 \\
B=[3.196] \\
\alpha=[0.308] \\
\omega=[0.741] \\
\varphi=[3.970]\end{array}$ & $\gamma$ & $\begin{array}{l}O_{-} \mathrm{F}=0.081 \\
A=6.681 \\
k=1 \\
B=[2.186] \\
\alpha=[0.968] \\
\omega=[4.230] \\
\varphi=[0.647]\end{array}$ & $r$ \\
\hline $\begin{array}{l}O_{A} \mathrm{~F}=0.072 \\
A=7.2 \\
k=1 \\
B=[2.512] \\
\alpha=[0.905] \\
\omega=[4.035] \\
\varphi=[0.761]\end{array}$ & $A$ & $\begin{array}{l}O_{-} \mathrm{F}=0.077 \\
A=6.70 \\
k=1 \\
B=[2.857] \\
\alpha=[0.692] \\
\omega=[3.733] \\
\varphi=[1.048]\end{array}$ & $r$ \\
\hline $\begin{array}{l}O_{-} F=0.09 \\
A=9.442 \\
k=1 \\
B=[4.5960] \\
\alpha=[0.612] \\
\omega=[4.298] \\
\varphi=[0.297]\end{array}$ & 9 & $\begin{array}{l}O_{-} F=0.161 \\
A=9.345 \\
k=1 \\
B=[5.788] \\
\alpha=[0.399] \\
\omega=[4.487] \\
\varphi=[0.486]\end{array}$ & + \\
\hline $\begin{array}{l}O_{-} \mathrm{F}=0.190 \\
A=6.117 \\
k=1 \\
B=[2.609] \\
\alpha=[0.671] \\
\omega=[3.613] \\
\varphi=[1.085]\end{array}$ & 1. & $\begin{array}{l}O_{-} \mathrm{F}=0.147 \\
A=9.344 \\
k=1 \\
B=[5.80] \\
\alpha=[0.401] \\
\omega=[4.495] \\
\varphi=[0.494]\end{array}$ & $\Delta$ \\
\hline
\end{tabular}

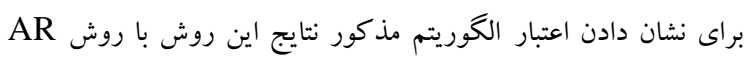

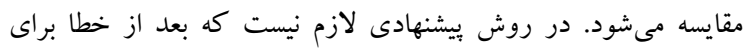

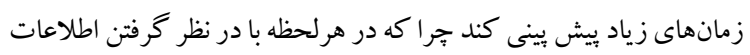

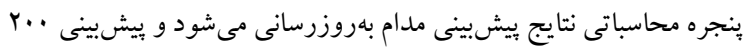

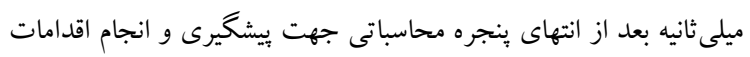

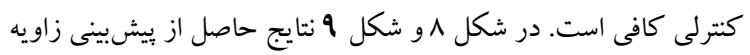

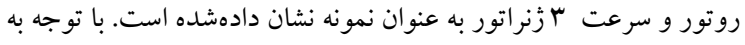

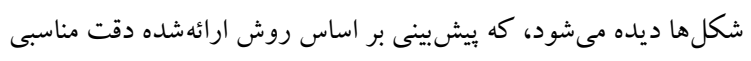

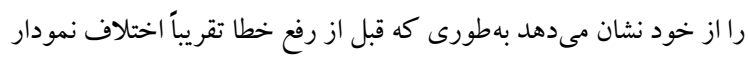

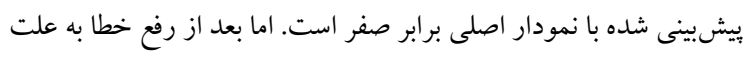

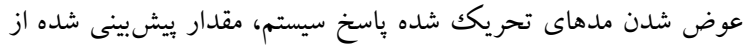

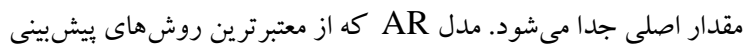
سرى زمانى است داراى دقت مناسبى بوده كه درمجموع يشيش بينى بـ با مدل

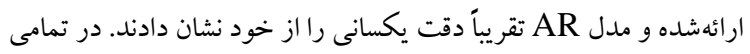
ييشبينى ها طول ينجرهى محاسباتى r/ • ثانيه در نظر گرفنه شده است. براى

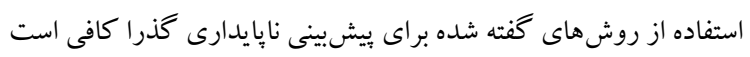


داراى شيب متفاوتى است لذا بايستى يك ناحيه بهصورت جزيره از شبكه

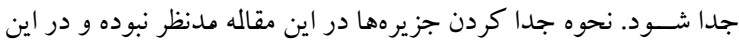

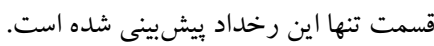
جدول r: نتايج بيش بينى براى حالت جزيره شدگى با تابع هدف

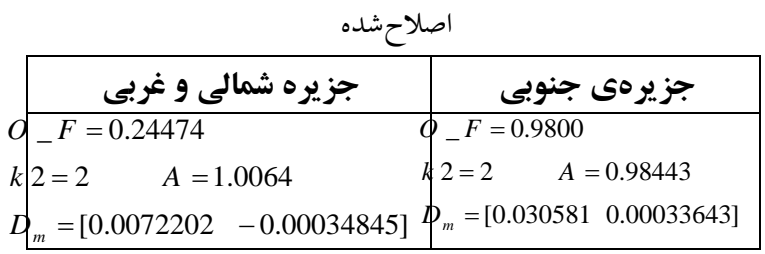

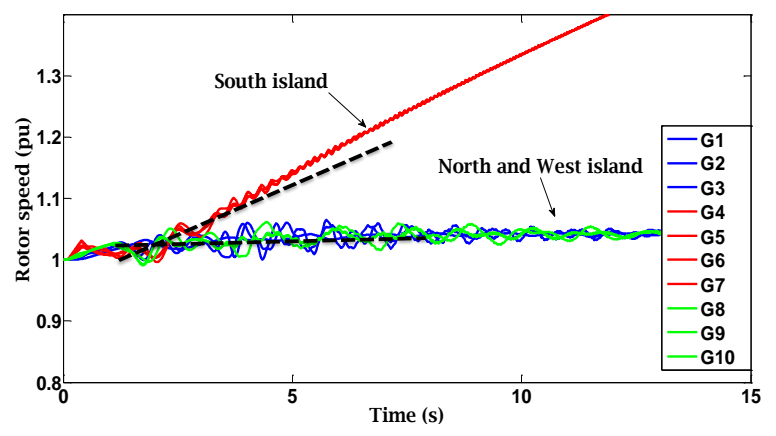

شكل 11: نحوهى تغييرات سرعت زنراتورها بعد از اعمال خطاى شافاز در باس 19 و با رفع خطاى ..rاميلى ثانيه

تـداخل اين روش بـا نوســان توان و ادوات جبران كر.. وجود نخو اهـــ

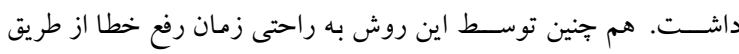
تشـخيص افزايش تابع هدف قابل تخمين اسـت. و بعد از تخمين رفع خطا

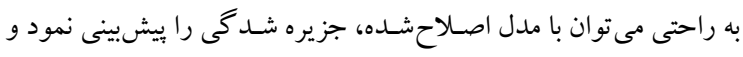
شرايط را براى اقدامات كنترل جزيره شدگى مهيا ساخت.

\section{ج- نتيجه تيرى}

جزيره شدگى ناخواسته فرايندى است كه بايد با توجه به تويولوزى

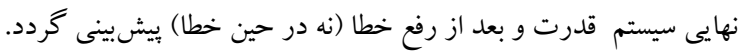
از آنجايى كه در روشهاى بيشيينى كه تاكنون در اين راستا ارائه شده

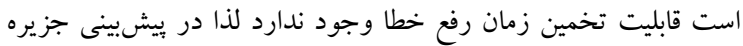

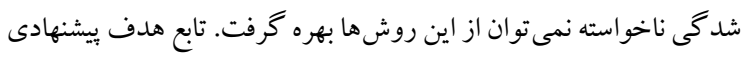
با توجه به مدهاى تحريككشده در حين اغتشاش و بعد از اغتشاش مدل كرديد تا با تغيير تويولوزى در هرلحظهاى تابع هدف نداى داراى تغييرات

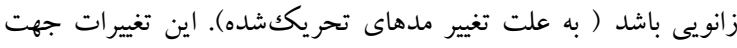

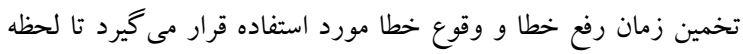

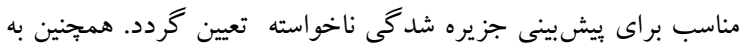

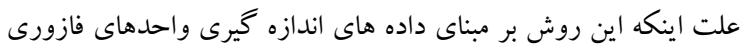

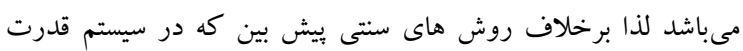

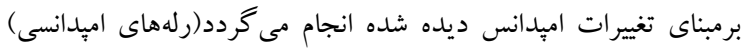
دجار هم بوشانى با رخداد هاى ديخر (مثل نوسان توان ) نخو ادهد بوده.

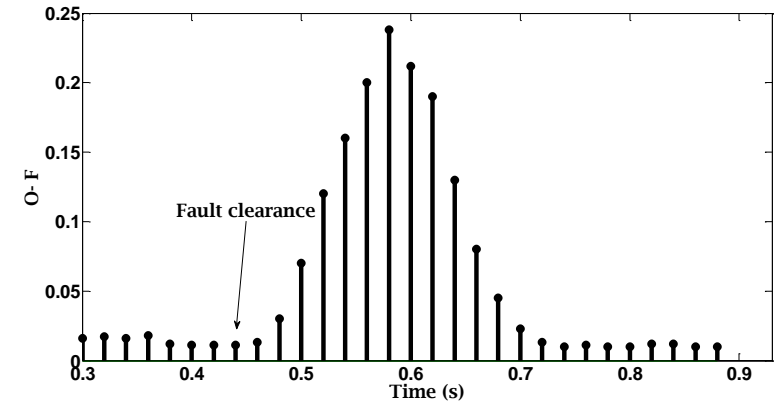

شكل • ا: نحوهى تغييرات تابع هدف براى يكك ماشين با رفع خطا در

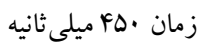

$O_{-} F=\sum_{N=1}^{N_{t}}\left|\left[A+\sum_{n=1}^{k} B_{n} e^{\alpha_{n} t} \times \sin \left(\omega_{n} t+\varphi_{n}\right)+\sum_{m=1}^{k_{2}} D_{m} t^{m}\right]-\mathrm{y}_{N}\right|$

$k_{2}=1$ or 2

كه در آن

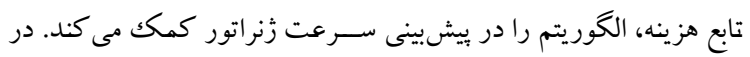
شـ ايط جزيره شـدگى تفريق سـرعت زنراتورها از

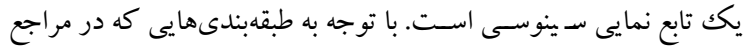

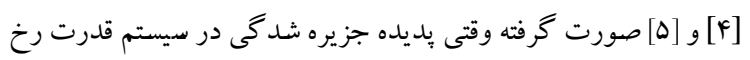

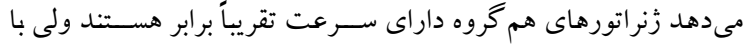

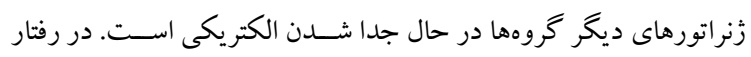

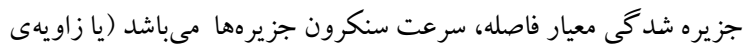

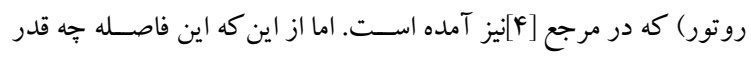

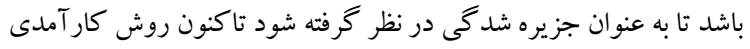

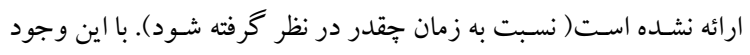
مقدار آستانه اين فاصسله تأثيرى در كارايى روش بيشـنهادى در اين مقاله

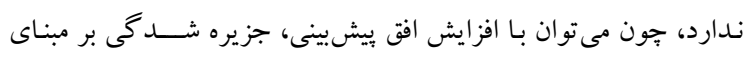

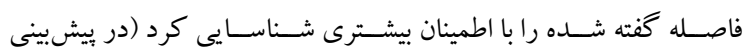

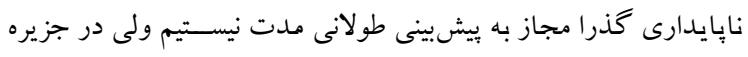

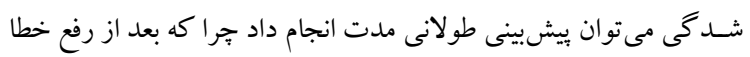

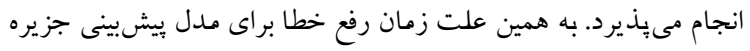

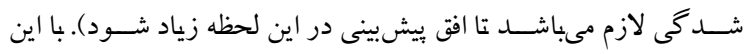
توضيحات نيازى به تخمين قسمت نوسانى تابع هدف معادله (F) نبوده و تنها

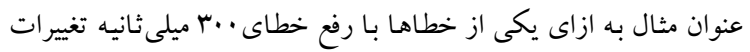
سرعت زنراتورها درشكل ل النشان دادهشده است. با توجه به اين شكل رئل

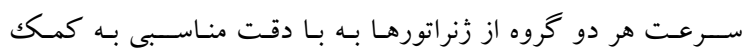
$A+\sum_{m=1}^{k 2} D_{m} t^{m}$ دادهشـده اسـت. نتايج هر دو بهينهـ ازى به كمكك روش SBB GAMS توجه به اين خطوط كه قبل از شـروع جزيره شـدى تحى تخمين زده شـدهاند.

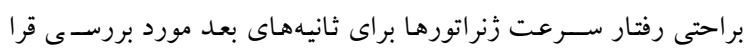

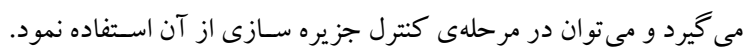

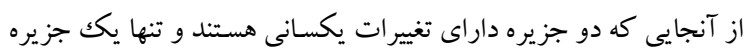


Modulated Particle Swarm Optimization based islanding of large-scale power systems." Advanced Engineering Informatics 23, no. 1 (2009): 45-56.

[8] You, Haibo, Vijay Vittal, and Xiaoming Wang. "Slow coherency-based islanding." Power Systems, IEEE Transactions on 19, no. 1 (2004): 483-491.

[9] Sun, Kai, Tarlochan S. Sidhu, and Ming Jin. "Online pre-analysis and real-time matching for controlled splitting of large-scale power networks." In Future Power Systems, 2005 International Conference on, pp. 6-pp. IEEE, 2005.

[10] Sun, Kai, Kyeon Hur, and Pei Zhang. "A new unified scheme for controlled power system separation using synchronized phasor measurements." IEEE Transactions on Power Systems 26, no. 3 (2011): 1544-1554.

[11] Senroy, Nilanjan, and Gerald T. Heydt. "Timing of a controlled islanding strategy." In 2005/2006 IEEE/PES Transmission and Distribution Conference and Exhibition, pp. 1460-1466. IEEE, 2006.

[12] Kamali, Sadegh, Turaj Amraee, and Seyed Mohammad Taghi Bathaee. "Prediction of unplanned islanding using an energy based strategy." IET Generation, Transmission \& Distribution 10, no. 1 (2016): 183-191.

[13] Isazadeh, Ghader, Amin Khodabakhshian, and Eskandar Gholipour. "New intelligent controlled islanding scheme in large interconnected power systems." IET Generation, Transmission \& Distribution 9, no. 16 (2015): 2686-2696.

[14] Adibi, M. M., R. J. Kafka, Sandeep Maram, and Lamine M. Mili. "On power system controlled separation." Power Systems,

IEEE Transactions on 21, no. 4 (2006): 1894-1902.

[15] Yang, Bo, Vijay Vittal, and Gerald T. Heydt. "Slow-Coherency-Based Controlled Islanding\&\# 8212; A Demonstration of the Approach on the August 14, 2003 Blackout Scenario." Power Systems, IEEE Transactions on 21, no. 4 (2006): 1840-1847.

[16] Marple Jr, S. Lawrence. "Digital spectral analysis with applications." Englewood Cliffs, NJ, Prentice-Hall, Inc., 1987, 512 p. 1 (1987).

[17] Ljung, Lennart. System identification. Birkhäuser Boston, 1998.

[18] http://psdyn.ece.wisc.edu/IEEE_benchmarks

$$
\begin{aligned}
& \text { در اين مقاله براى ييشينى سيخنال زمانى سرعت و زاويه روتور }
\end{aligned}
$$

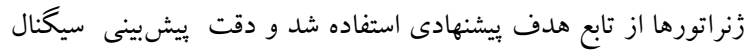

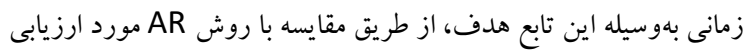

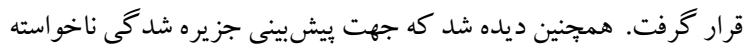

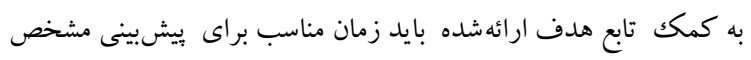

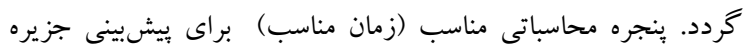

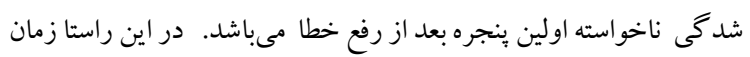

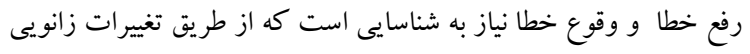

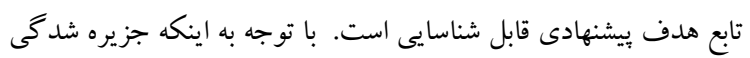

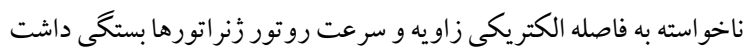

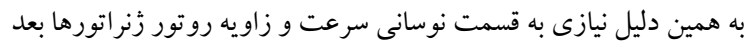

$$
\begin{aligned}
& \text { از رفع خطا نبود در نتيجه تابع هدف اصلاح شده به كمكك اطلاعات }
\end{aligned}
$$

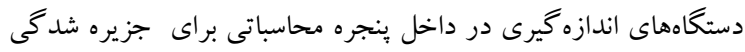

$$
\begin{aligned}
& \text { استفاده شد. } \\
& \text { نتايج شبيه سازى در شبكه استاندارد وب باسه IEEE به ازاى سناريوى }
\end{aligned}
$$

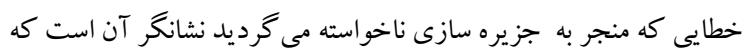

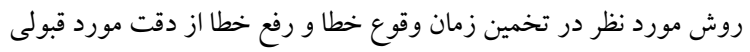

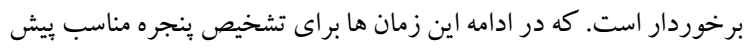

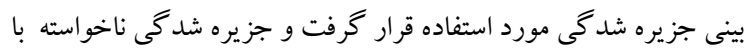

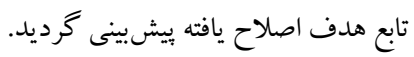

$$
\begin{aligned}
& \text { مر 'جع }
\end{aligned}
$$

[1] Power swing and out-of-step consideration on transmission lines IEEE PSRC WG D6

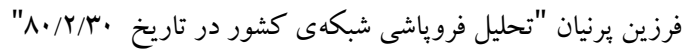

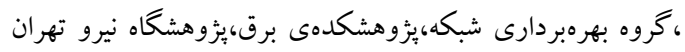

$$
\begin{aligned}
& \text { 6 ايران }
\end{aligned}
$$

[3] M.Sanaye-pasand," scrutiny of the Iranian national grid", IEEE power \& energy magazine, 2007.

[4] Senroy, Nilanjan, Gerald T. Heydt, and Vijay Vittal. "Decision tree assisted controlled islanding." Power Systems, IEEE Transactions on 21, no. 4 (2006): 1790-1797

[5] Xu, Guangyue, Vijay Vittal, Anatoliy Meklin, and Jon Eric Thalman. "Controlled islanding demonstrations on the WECC system." Power Systems, IEEE Transactions on 26, no. 1 (2011): 334-343.

[6] Ahmed, S. Shahnawaz, Narayan Chandra Sarker, Azhar B. Khairuddin, Mohd Ruddin B. Abd Ghani, and Hussein Ahmad. "A scheme for controlled islanding to prevent subsequent blackout." Power Systems, IEEE Transactions on 18, no. 1 (2003): 136-143.

[7] Liu, Li, Wenxin Liu, David A. Cartes, and IlYop Chung. "Slow coherency and Angle 